\title{
METHOD OF FORMULATING THE REQUIRED NUMBER OF VEHICLES FOR DELIVERY AIRCRAFTS IN AVIATION FUEL
}

\section{METODA OBLICZANIA MINIMALNEJ LICZBY POJAZDÓW DOSTARCZAJĄCYCH PALIWA LOTNICZE STATKOM POWIETRZNYM}

\author{
Józef Żurek ${ }^{1)}$, Jarosław Ziółkowski ${ }^{2)}$ \\ ${ }^{1)}$ Instytut Techniczny Wojsk Lotniczych. ${ }^{2)}$ Wojskowa Akademia Techniczna \\ Abstract: An important part of the air base logistic system is the supply sub-system. \\ In military operations the main delivery can be focused on munitions and aviation \\ fuel. Effective management of the supply stream and the reliability of vehicles in \\ the air base logistic system affect the quality of operations, which can be measured \\ by on time provisions, economic factors and the reliability of vehicles. At present \\ the number of tankers in the air base logistic system is based on experiences.
}

Keywords: vehicles, delivery, optimization

Streszczenie: $W$ czasie wykonywania lotów przez statki powietrzne zasadnicze kwestie stanowia gotowość bojowa oraz majacy na nia wptyw system zaopatrywania. Podstawowymi przedmiotami zaopatrzenia $w$ czasie realizacji zadań sq środki bojowe i paliwa lotnicze. Skuteczne zarzadzanie przeptywem wymaganych produktów a także niezawodność pojazdów i dyspozycyjność załogi wptywaja na jakość wykonania zadania. Składowe tworzące tę jakość $w$ działaniach wojskowych sa mierzone gotowościa. W rzeczywistych systemach eksploatacji liczba pojazdów zasilajacych statki powietrzne w paliwa lotnicze jest określona ze względu na bezpieczeństwo i niezawodność z nadmiarem odniesionym do liczby obiektów zabezpieczajacych loty.

$W$ artykule opracowano metode wyznaczania niezbędnej liczby pojazdów niezbędnych do zasilania sp w paliwa lotnicze.

Stowa kluczowe: pojazdy, dostarczanie, optymalizacja 
Method of formulating the required number of vehicles for delivery aircrafts... Metoda obliczania minimalnej liczby pojazdów dostarczajacych paliwa lotnicze...

\section{Wprowadzenie}

W czasie realizacji zadań w systemach lotniczych niezbędne z punktu widzenia osiągnięcia założonego celu są: niezawodność oraz bezpieczeństwo eksploatacji statków powietrznych $[8,9]$. Teoria dotycząca matematycznych modeli oraz metod stosowanych $\mathrm{w}$ niezawodności oraz gotowości obiektów technicznych została przedstawiona $\mathrm{w}$ pracach $[1,4,6,7]$. W rzeczywistości do badań oraz analizy procesów, obiektów czy też systemów eksploatacji wykorzystuje się rachunek prawdopodobieństwa oraz statystykę matematyczną [3], ze względu na fakt, że modelowanie matematyczne odnosi się do procesów stochastycznych [2,3].

W systemach eksploatacji statków powietrznych Su-22 będących na wyposażeniu 21 Bazy Lotnictwa Taktycznego w Świdwinie liczba pojazdów dostarczających paliwo lotnicze wynika $\mathrm{z}$ doświadczeń. Mając na uwadze niezawodność podsystemu dostarczającego paliwa rzeczywista liczba jest określona z nadmiarem strukturalnym.

W niniejszym artykule zaproponowano metodę matematyczną umożliwiającą wyznaczenie minimalnej liczby pojazdów o dowolnej pojemności, która zapewni dostawy potrzebnej ilości paliwa lotniczego podczas wykonywania lotów.

\section{Założenia do budowy modelu matematycznego}

Do budowy matematycznego modelu umożliwiającego obliczenie niezbędnej liczby pojazdów dostarczających paliwa statkom powietrznym przyjęto następujące założenia [5,6]:

- pojazd w dowolnej chwili może znajdować się w jednym z wyróżnionych stanów eksploatacyjnych;

- liczba statków powietrznych uczestniczących w lotach jest zmienną losową skokową;

- współczynnik opróżnienia zbiornika zasadniczego statku powietrznego jest zmienną losową przyjmującą wartości $K_{z u} \in\{0,33 ; 0,5 ; 0,66 ; 0,85\}$;

- pojazdy uszkadzają się w trakcie realizacji zadań w losowych chwilach czasu;

- czas odnowy (zamiany na sprawny technicznie) pojazdu jest ściśle zdeterminowany;

- czas trwania lotów $\left(T_{0}\right)$ jest ustalony, zgodny z tabelą lotów.

Do opracowania modelu przyjęto następujące zmienne decyzyjne:

- liczba statków powietrznych $-N_{S P}$;

- pojemność zbiornika (ów) zasadniczego (ych) statku powietrznego - $V_{z b s p}$;

- współczynnik opróżnienia zbiornika statku powietrznego - $K_{z u}$;

- liczba pojazdów - $N_{P}$;

- pojemność pojazdu zaopatrującego statki powietrzne w paliwo lotnicze $-V_{P}$;

- organizacja lotów (zgodna z planową tabelą lotów). 
Równanie bilansu paliwa dla jednego wylotu statku powietrznego $s p$ zgodnie z założonym czasem trwania lotów $T_{0}$ można wyznaczyć według zależności:

$$
\sum_{k=1}^{N_{s p}}{ }_{k} K_{z u} \cdot V_{z b s p}=V_{e l t 1}
$$

gdzie:

$N_{S P}$ - liczba wylotów statku powietrznego;

$k=1,2, \ldots$, oznacza numer statku powietrznego.

Równanie bilansu zużytego paliwa dla maksymalnej liczby wylotów statków powietrznych $s p$ eskadry lotnictwa taktycznego elt można zapisać jako:

$$
\sum_{k}^{N_{S P}} \sum_{l}^{N_{e l t}}\left({ }_{l k} K_{z u}\right) \cdot V_{z b s p}=V_{e l t \max }
$$

gdzie:

${ }_{l k} N_{\text {elt }}-l$-ty wylot $k$-tego $s p$ eskadry lotnictwa taktycznego;

${ }_{l k} K_{z u}-$ współczynnik zużycia paliwa dla $l$-tego wylotu $k$-tego statku powietrznego;

$N_{\text {elt }} \in\{1, \ldots, 8\}$ liczba wylotów elt.

Zależność (2) uwzględnia założenie, że latały wszystkie statki powietrzne. Jeżeli tak nie będzie, to należy przyjąć dla $l$-tego wylotu $k$-tego $s p$ zero $\left({ }_{l k} K_{z u}=0\right)$.

Stan tankowania statków powietrznych rozważono dla dwóch sytuacji:

1) przy zerowym czasie oczekiwania $\left(t_{o c z}=0\right)$;

gdzie:

$$
t_{4}=t_{m}+K_{z u} \times t_{e t}
$$

$t_{4}-$ czas uzupełniania paliwa $s p$;

$t_{m}$ - czas manipulacyjny (związany z czasem dojazdu pojazdu do $s p$, czasem potrzebnym na podłączenie końcówki do tankowania itp.);

$K_{z u}$ - współczynnik opróżnienia zbiornika sp;

$t_{e t} \quad$ - czas tankowania całkowicie opróżnionego zbiornika $s p$ przez pojazd.

2) przy założeniu maksymalnej częstości wylotów (np. wylot co $40 \mathrm{~min}$ ), dla którego $t_{o c z} \in\left(40 \mathrm{~min}\right.$. - $\left.\mathrm{t}_{4}\right)$.

Dla $K_{z u}=0,85$ przy uwzględnieniu $T_{0}=8 \mathrm{~h}$, otrzymuje się dla eskadry $N_{\text {elt }}=5$. Stąd maksymalna ilość paliwa zużytego przez elt wynosi:

$$
V_{\text {elt } \max }=\sum_{k=1}^{16} \sum_{l=1}^{5} K_{z u} \cdot V_{z b s p}=314500\left[\mathrm{dm}^{3}\right]
$$


Method of formulating the required number of vehicles for delivery aircrafts...

Metoda obliczania minimalnej liczby pojazdów dostarczajacych paliwa lotnicze...

Równania bilansowe pojemności i czasu pracy dla pojazdu opisano zależnościami (5) i (6):

a) bilans pojemności:

$$
N_{P V} \cdot V_{P} \geq V_{\text {elt } \max } \quad \text { stąd: } \quad N_{P V} \geq \frac{V_{\text {elt max }}}{V_{P}}
$$

gdzie:

$N_{P V}$ - liczba pojazdów potrzebnych objętościowo do przewozu całego paliwa zużytego w czasie wykonywania lotów;

$V_{P} \quad-$ pojemność pojazdu;

$V_{\text {eltmax }}$ - maksymalne zużycie paliwa przez elt w czasie wykonywania lotów.

$$
N_{P V} \geq\left\{\begin{array}{lll}
69,889 & \text { dla } & V_{P-4,5} \\
41,933 & \text { dla } & V_{P-7,5}
\end{array}\right\}
$$

b) bilans czasów: założono, że czas potrzebny na cykl uzupełnienia paliwa przez pojazd $t_{5}$ musi spełniać warunek:

gdzie:

$$
t_{5} \leq t_{n P V}+t_{m}+t_{2}+t_{3}
$$

$t_{n P V}$ - czas napełniania pojazdu o określonej pojemności, uzależniony od stopnia jego opróżnienia;

$t_{m} \quad$ - czas manipulacyjny, związany $\mathrm{z}$ dojazdem pojazdu do magazynu i czynnościami przygotowawczymi do tankowania (np. podłączenie końcówek) oraz z powrotem na płytę lotniska;

$t_{2}$ - wymagany czas odstania paliwa;

$t_{3}-$ czas realizacji kontroli jakości paliwa w pojeździe.

Założono, że pojazd może wykonać w czasie realizacji lotów $T_{0}$ co najwyżej $N_{5}$ cykli uzupełniania paliwa. Równanie bilansu czasu pracy dla jednego pojazdu potrzebne jest do badania realności rozważanego procesu i można je zapisać w następujący sposób:

$$
\begin{gathered}
t_{5} \cdot N_{5}+t_{4} \cdot N_{4} \leq T_{0} \\
N_{5} \leq \frac{T_{0}}{t_{5}} \quad N_{4} \leq \frac{T_{0}}{t_{4}}
\end{gathered}
$$

gdzie:

$t_{5}$ - czas cyklu uzupełniania paliwa przez pojazd;

$N_{5}$ - liczba cykli uzupełniania paliwa przez pojazd;

$t_{4}$ - czas tankowania $s p$

$N_{4}-$ liczba tankowań $s p ;$

$T_{0}$ - czas trwania lotów.

Jeżeli $V_{P} \approx V_{z b s p}$, to dla jednego pojazdu musi być $N_{4}=N_{5}$ i powstanie rezerwa czasowa, z reguły $t_{4} \neq t_{5}$, a w praktyce $t_{4}<<t_{5}$. 
Liczbę pojazdów potrzebnych objętościowo $N_{P V}$ do przewozu całego paliwa zużywanego przez elt należy przetworzyć na liczbę pojazdów potrzebnych fizycznie $N_{P}$ według wzoru:

$$
N_{P} \geq \frac{N_{P V}}{N_{5}}
$$

gdzie:

$N_{P}$ - liczba pojazdów potrzebnych fizycznie do zabezpieczenia lotów;

$N_{P V}$ - liczba pojazdów potrzebnych objętościowo do przewozu potrzebnej ilości paliwa w jednym rejsie;

$N_{5}$ - liczba możliwych cykli uzupełniania paliwa przez pojazd.

Na podstawie przyjętych założeń otrzymuje się następujące równania/nierówności:

$$
\begin{gathered}
\sum_{k}^{N_{S P}} \sum_{l}^{k_{e l t}}\left({ }_{l k} K_{z u}\right) \cdot V_{z b s p}=V_{e l t \max } \\
N_{P V} \geq \frac{V_{e l t \max }}{V_{P}} \\
N_{P} \geq \frac{N_{P V}}{N_{5}} \\
t_{5} \cdot N_{5}+t_{4} \cdot N_{4} \leq T_{0} \\
N_{5} \cdot V_{P} \geq N_{4} \cdot V_{z b s p} \cdot K_{z u}
\end{gathered}
$$

z których można wyznaczyć obszar dopuszczalnych rozwiązań przy założonych ograniczeniach.

\section{Przykład liczbowy}

W celu praktycznego zastosowania opracowanej metodyki obliczeń przyjęto następujące zmienne decyzyjne:

- czas trwania lotów $T_{0}=480$ [min].;

- liczba statków powietrznych realizująca loty - 8;

- loty są wykonywane na samolotach Su-22;

- współczynnik zużycia paliwa jest uzależniony od długości lotu i przyjmuje następujące wartości $K_{z u}=\{0,33 ; 0,5 ; 0,66 ; 0,85)$;

- organizacja lotów jest zgodna z planową tabelą lotów (rys. 1). 
Method of formulating the required number of vehicles for delivery aircrafts... Metoda obliczania minimalnej liczby pojazdów dostarczajacych paliwa lotnicze...

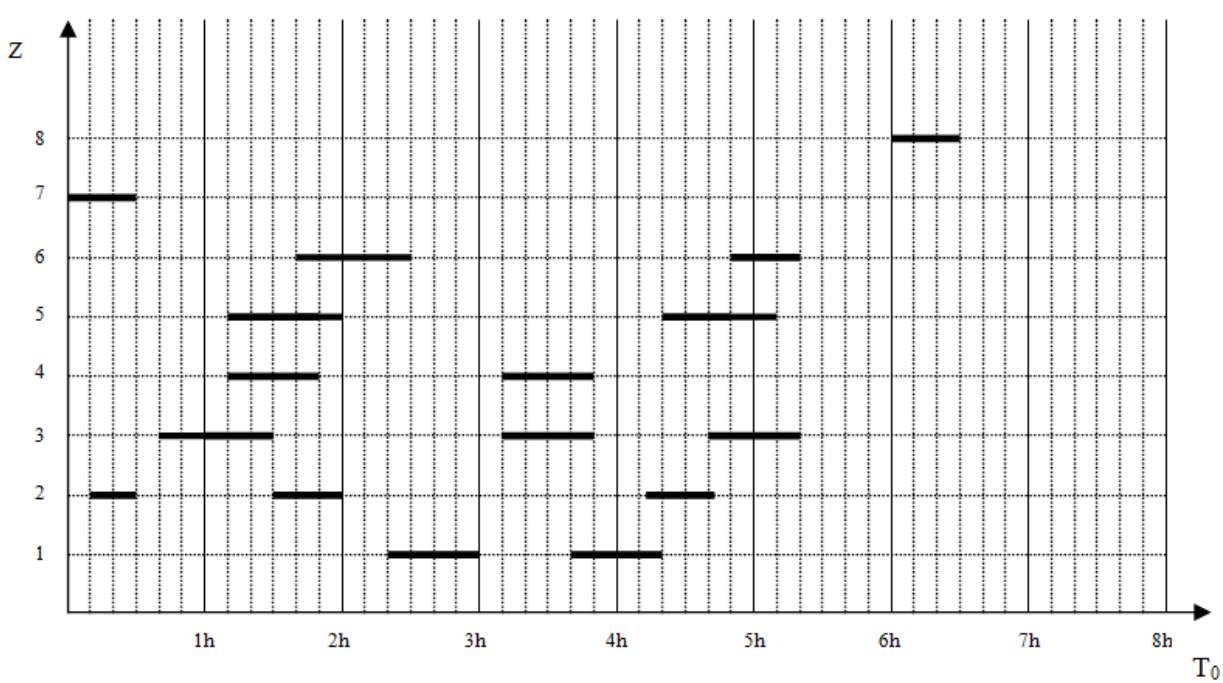

Rys. 1. Planowa tabela lotów - wariant: $T_{0}$ - czas wykonywania lotów, Z - liczba statków powietrznych

Należy obliczyć minimalną, zapewniającą ciągłość lotów, liczbę pojazdów o pojemności $7,5\left[\mathrm{~m}^{3}\right]$, wystarczającą do zabezpieczenia odpowiedniej ilości paliwa lotniczego.

Rozwiązanie:

Zgodnie z zależnością (10) należy obliczyć ilość paliwa zużytego przez $s p$ w czasie wykonywania lotów:

$V_{e l t}=\sum_{k}^{N_{s p}} \sum_{l}^{N_{c l t}}\left({ }_{l k} K_{z u}\right) \cdot V_{z b s p}=47128,75\left[\mathrm{dm}^{3}\right]$

Ponieważ długość lotu statku powietrznego jest opisana zmienną losową skokową, dla której współczynnik opróżnienia zbiornika paliwa $s p$ przyjmuje wartości ze zbioru $K_{z u}=\{0,33 ; 0,5 ; 0,66 ; 0,85\}$, potrzebną liczbę pojazdów należy obliczać dla wyżej wymienionych wartości $K_{z u}$ w czterech przypadkach, a następnie otrzymane wyniki cząstkowe zsumować.

\section{Przypadek I}

Obliczenia ilości zużytego paliwa lotniczego dla $K_{z u}=0,85$

$V_{0,85}=0,85\left(1 * V_{3 \mathrm{zbsp}}+2 * V_{5 \mathrm{zbsp}}+1 * V_{6 \mathrm{zbsp}}\right)=15725\left[\mathrm{dm}^{3}\right]$

Określona liczba pojazdów o ustalonej pojemności zgodnie z zależnością (11) musi być większa bądź równa od potrzebnej ilości paliwa:

a zatem:

$$
\begin{gathered}
N_{P V} \cdot V_{P} \geq V_{\text {elt }} \\
N_{P V} \geq \frac{V_{\text {elt }}}{V_{P}} \geq \frac{15725}{7500} \geq 2,09 \approx 3
\end{gathered}
$$


Czas cyklu uzupełniania paliwa przez pojazd składa się z sumy czasów potrzebnych na: dojazd pojazdu do magazynu, czasu manipulacyjnego, właściwego czasu tankowania, czasu powrotu na płytę lotniska, czasu odstania paliwa oraz kontroli jego czystości i wynosi on:

$$
t_{5}=3,27+54=57,27[\mathrm{~min} .]
$$

Czas tankowania $s p$ jest ściśle określony, gdyż zależy od: współczynnika $K_{z u}$ opróżnienia zbiornika $s p$, wydajności dystrybutora i czasu dojazdu zatankowanego pojazdu do statku powietrznego:

$$
t_{4}=0,85 * 4625 / 300+5=18,11[\mathrm{~min} \text {.] }
$$

Liczbę cykli uzupełniania paliwa zarówno przez pojazd $N_{5}$, jak i liczbę tankowań statku powietrznego $N_{4}$ należy obliczyć zgodnie z zależnościami (l3 $\mathrm{i}$ 14) rozwiązując poniższy układ nierówności:

$$
\begin{gathered}
\left\{\begin{array}{c}
t_{5} \cdot N_{5}+t_{4} \cdot N_{4} \leq T_{0} \\
N_{5} \cdot V_{P} \geq N_{4} \cdot V_{z b s p} \cdot K_{z u}
\end{array}\right. \\
N_{5} \leq \frac{T_{0}}{t_{5}}-\frac{t_{4} \cdot N_{4}}{t_{5}} \leq \frac{480}{57,27}-\frac{10,08 \cdot N_{4}}{57,27} \leq 8,38-0,176 N_{4} \\
N_{5} \geq \frac{K_{z u} \cdot V_{z b s p} \cdot N_{4}}{V_{P-7,5}} \geq \frac{0,85 \cdot 4625 \cdot N_{4}}{7500} \geq 0,5241 N_{4} \\
8,38-0,176 N_{4}=0,5241 N_{4} \\
0,7001 N_{4}=8,38 \Rightarrow N_{4}=11,9697 \\
N_{5} \geq 0,5241 N_{4} \geq 6,27 \approx 7
\end{gathered}
$$

Po podstawieniu obliczonych $N_{P V}$ oraz $N_{5}$ do wzoru (12) otrzymuje się:

$$
N_{P 0,85} \geq \frac{N_{P V}}{N_{5}} \geq \frac{3}{7}=0,43
$$

\section{Przypadek II}


Method of formulating the required number of vehicles for delivery aircrafts...

Metoda obliczania minimalnej liczby pojazdów dostarczajacych paliwa lotnicze...

Obliczenia ilości zużytego paliwa lotniczego dla $K_{z u}=0,66$

$V_{0,66}=0,66\left(2 * \mathrm{~V}_{1 \mathrm{zbsp}}+2 * \mathrm{~V}_{3 \mathrm{zbsp}}+2 * \mathrm{~V}_{4 \mathrm{zbsp}}\right)=18315\left[\mathrm{dm}^{3}\right]$

Określona liczba pojazdów o ustalonej pojemności zgodnie z zależnością (11) musi być większa bądź równa od potrzebnej ilości paliwa, według poniższego wzoru:

$$
\begin{gathered}
N_{P V} \cdot V_{P} \geq V_{\text {elt }} \\
N_{P V} \geq \frac{V_{\text {elt }}}{V_{P}} \geq \frac{18315}{7500} \geq 2,442 \approx 3
\end{gathered}
$$

Czas cyklu uzupełniania paliwa przez pojazd składa się $\mathrm{z}$ sumy czasów potrzebnych na: dojazd pojazdu do magazynu, czasu manipulacyjnego, właściwego czasu tankowania, czasu powrotu na płytę lotniska, czasu odstania paliwa oraz kontroli jego czystości i dla $K_{z u}=0,66$ wynosi on:

$$
t_{5}=2,54+54=56,54 \text { [min.] }
$$

Czas tankowania $s p$ jest ściśle określony, gdyż zależy od: współczynnika $K_{z u}$ opróżnienia zbiornika $s p$, wydajności dystrybutora i czasu dojazdu zatankowanego pojazdu do statku powietrznego:

$$
t_{4}=0,66 * 4625 / 300+5=15,17 \text { [min.] }
$$

Liczbę cykli uzupełniania paliwa zarówno przez pojazd $N_{5}$, jak i liczbę tankowań statku powietrznego $N_{4}$ należy obliczyć zgodnie $\mathrm{z}$ zależnościami (13 $\mathrm{i}$ 14) rozwiązując poniższy układ nierówności:

$$
\begin{gathered}
\left\{\begin{array}{c}
t_{5} \cdot N_{5}+t_{4} \cdot N_{4} \leq T_{0} \\
N_{5} \cdot V_{P} \geq N_{4} \cdot V_{z b s p} \cdot K_{z u}
\end{array}\right. \\
N_{5} \leq \frac{T_{0}}{t_{5}}-\frac{t_{4} \cdot N_{4}}{t_{5}} \leq \frac{480}{56,54}-\frac{15,17 \cdot N_{4}}{56,54} \leq 8,48-0,268 N_{4} \\
N_{5} \geq \frac{K_{z u} \cdot V_{z b s p} \cdot N_{4}}{V_{P-7,5}} \geq \frac{0,66 \cdot 4625 \cdot N_{4}}{7500} \geq 0,407 N_{4} \\
8,48-0,268 N_{4}=0,407 N_{4} \\
0,675 \mathrm{~N}_{4}=8,48 \Rightarrow \mathrm{N}_{4}=12,56 \\
N_{5} \geq 0,407 N_{4} \geq 5,11=6
\end{gathered}
$$

Po podstawieniu obliczonych $N_{P V}$ oraz $N_{5}$ do wzoru (12) otrzymuje się:

$$
N_{P 0,66} \geq \frac{N_{P V}}{N_{5}} \geq \frac{3}{6}=0,5
$$




\section{Przypadek III}

Obliczenia ilości zużytego paliwa lotniczego dla $K_{z u}=0,5$

$V_{0,5}=0,5\left(2 * \mathrm{~V}_{2 \mathrm{zbsp}}+\mathrm{V}_{6 \mathrm{zbsp}}+\mathrm{V}_{7 \mathrm{zbsp}}+\mathrm{V}_{8 \mathrm{zbsp}}\right)=11562,5\left[\mathrm{dm}^{3}\right]$

Określona liczba pojazdów o ustalonej pojemności musi być większa/równa od potrzebnej ilości paliwa. Zatem oblicza się ją według poniższej zależności:

$$
\begin{gathered}
N_{P V} \cdot V_{P D} \geq V_{\text {elt } \max } \\
N_{P V} \geq \frac{V_{\text {elt }}}{V_{P}} \geq \frac{11562,5}{7500} \geq 1,54 \approx 2
\end{gathered}
$$

Czas $t_{5}$ cyklu uzupełniania paliwa przez pojazd wynosi:

$$
t_{5}=1,927+54=55,927 \text { [min.] }
$$

Czas tankowania $s p$ zależy od: pojemności zbiornika $s p$ współczynnika opróżnienia zbiornika $K_{z u}$, wydajności dystrybutora i czasu dojazdu zatankowanego pojazdu do statku powietrznego:

$$
t_{4}=0,5 * 4625 / 300+5=12,71 \text { [min.] }
$$

Liczbę cykli uzupełniania paliwa przez pojazd $N_{5}$, jak również liczbę tankowań statku powietrznego $N_{4}$ należy obliczyć zgodnie $\mathrm{z}$ zależnościami (13) i (14) rozwiązując poniższy układ nierówności:

$$
\begin{gathered}
\left\{\begin{array}{c}
t_{5} \cdot N_{5}+t_{4} \cdot N_{4} \leq T_{0} \\
N_{5} \cdot V_{P} \geq N_{4} \cdot V_{z b s p} \cdot K_{z u}
\end{array}\right. \\
N_{5} \leq \frac{T_{0}}{t_{5}}-\frac{t_{4} \cdot N_{4}}{t_{5}} \leq \frac{480}{55,927}-\frac{12,71 \cdot N_{4}}{55,927} \leq 8,58-0,227 N_{4} \\
N_{5} \geq \frac{K_{z u} \cdot V_{z b s p} \cdot N_{4}}{V_{P-7,5}} \geq \frac{0,5 \cdot 4625 \cdot N_{4}}{7500} \geq 0,308 N_{4} \\
8,58-0,227 N_{4}=0,308 N_{4} \\
0,535 \mathrm{~N}_{4}=8,58 \Rightarrow \mathrm{N}_{4}=16,03 \\
N_{5} \geq 0,308 N_{4} \geq 4,93=5
\end{gathered}
$$

Po podstawieniu obliczonych $N_{P V}$ oraz $N_{5}$ do wzoru (12) otrzymuje się:

$$
N_{P 0,5} \geq \frac{N_{P V}}{N_{5}} \geq \frac{2}{5}=0,4
$$


Method of formulating the required number of vehicles for delivery aircrafts...

Metoda obliczania minimalnej liczby pojazdów dostarczajacych paliwa lotnicze...

\section{Przypadek IV}

Obliczenia ilości zużytego paliwa lotniczego dla $K_{z u}=0,33$

$$
V_{0,33}=0,33\left(\mathrm{~V}_{2 \mathrm{zbsp}}\right)=1526,25\left[\mathrm{dm}^{3}\right]
$$

Określona liczba pojazdów o ustalonej pojemności musi być większa/równa od potrzebnej ilości paliwa, a zatem jest ona obliczana jako:

$$
\begin{gathered}
N_{P V} \cdot V_{P} \geq V_{\text {elt } \max } \\
N_{P V} \geq \frac{V_{\text {elt }}}{V P} \geq \frac{1526,25}{7500} \geq 0,2=1
\end{gathered}
$$

Czas $t_{5}$ cyklu uzupełniania paliwa przez pojazd wynosi:

$$
t_{5}=1,27+54=55,27 \text { [min.] }
$$

Czas tankowania $s p$ jest ściśle określony i wynosi:

$$
t_{4}=0,33 * 4625 / 300+5=10,08 \text { [min.] }
$$

Liczbę cykli uzupełniania paliwa przez pojazd $N_{5}$ jak i liczbę tankowań statków powietrznych $N_{4}$ należy obliczyć zgodnie z zależnościami (13) i (14) rozwiązując poniższy układ nierówności:

$$
\left\{\begin{array}{c}
t_{5} \cdot N_{5}+t_{4} \cdot N_{4} \leq T_{0} \\
N_{5} \cdot V_{C D} \geq N_{4} \cdot V_{z b s p} \cdot K_{z u}
\end{array}\right.
$$

Po podstawieniu danych otrzymuje się:

$$
\begin{gathered}
N_{5} \leq \frac{T_{0}}{t_{5}}-\frac{t_{4} \cdot N_{4}}{t_{5}} \leq \frac{480}{55,27}-\frac{10,08 \cdot N_{4}}{55,27} \leq 8,68-0,18 N_{4} \\
N_{5} \geq \frac{K_{z u} \cdot V_{z b s p} \cdot N_{4}}{V_{P-7,5}} \geq \frac{0,33 \cdot 4625 \cdot N_{4}}{7500} \geq 0,2035 N_{4} \\
8,68-0,18 N_{4}=0,2935 N_{4} \\
0,3835 N_{4}=8,68 \Rightarrow N_{4}=22,63 \\
N_{5} \geq 0,2035 N_{4} \geq 4,605=5
\end{gathered}
$$

Po podstawieniu obliczonych $N_{P V}$ oraz $N_{5}$ do wzoru (12) otrzymuje się:

$$
N_{P 0,33} \geq \frac{N_{P V}}{N_{5}} \geq \frac{1}{5}=0,2
$$

Wymaganą niezbędną liczbę pojazdów o pojemności $7,5\left[\mathrm{~m}^{3}\right]$ uzyskano w wyniku zsumowania liczebności cząstkowych dla przyjętych współczynników $K_{z u}$ stopnia opróżnienia zbiornika $s p$ zgodnie z zależnością:

$$
\begin{gathered}
N_{P-7,5}>N_{P 0,33}+N_{P 0,5}+N_{P 0,66}+N_{P 0,85} \\
\text { ponieważ } 0,43+0,5+0,4+0,2=1,53 \quad \text { zatem }=N_{P-7,5}>1,53 \Rightarrow 2
\end{gathered}
$$


Zaproponowana metoda jest uniwersalna i prezentuje przykład zastosowania aparatu matematycznego umożliwiającego połączenie teorii i praktyki w zakresie modelowania realnych procesów realizowanych w systemie logistycznym bazy lotniczej (BLot.).

\section{Zakończenie}

W artykule przedstawiono metodę obliczania niezbędnej liczby pojazdów o dowolnej pojemności dostarczających paliwa lotnicze (na obecną chwilę ilość pojazdów jest ustalana empirycznie i z określonym nadmiarem).

Wymagana ilość pojazdów jest uzależniona od:

- liczby i rodzaju $s p$ biorących udział w lotach;

- przyjętego planu lotów (planowa tabela lotów), tj. długości lotów oraz częstotliwości wylotów;

- pojemności zbiorników pojazdów dostarczających paliwo lotnicze;

- organizacji systemu uzupełnienia paliwa w pojazdach (czasy manipulacyjne, wydajności dystrybutora/ów; czas odstania paliwa, kontroli czystości, poziomu wyszkolenia czynnika ludzkiego).

Metodę można zmodyfikować poprzez współczynnik nadmiaru, który spowoduje zwiększenie niezbędnej liczby pojazdów oraz poprawi gotowość systemu.

\section{Literatura}

[1] Bobrowski D., Modele i metody matematyczne teorii niezawodności, WNT, Warszawa 1985.

[2] Decewicz A. Probabilistyczne modele badań operacyjnych, SGH, Warszawa 2011.

[3] Fisz M., Rachunek prawdopodobieństwa i statystyka matematyczna, PWN, 1967.

[4] Gniedenko B.W., Bielajew J. K., Sołowiew A.D., Metody matematyczne w teorii niezawodności, WNT, Warszawa 1968.

[5] Ziółkowski J., Method of formulating the required number of tankers for delivery aircrafts in aviation fuel, Zagadnienia eksploatacji maszyn 3(163) vol.45/2010, PAN, Institute for Sustainable Technologies - Radom, ISSN 0137-5474, s.75-87.

[6] Ziółkowski J., Analiza systemu logistycznego bazy lotniczej w aspekcie gotowości, rozprawa doktorska, ITWL, Warszawa 2004.

[7] Żurek J., Ziółkowski J. Metoda obliczania niezbędnej liczby cystern w systemie logistycznym bazy lotniczej. Wybrane zagadnienia logistyki stosowanej nr 3/2006, Kraków 2006, s. 246-253

[8] Żurek J., Bagiński A., Problems of safety in aviation, Problemy bezpieczeństwa w lotnictwie, Journal of Conbin, nr 3(6)/2008, s. 5-24. 
Method of formulating the required number of vehicles for delivery aircrafts...

Metoda obliczania minimalnej liczby pojazdów dostarczajacych paliwa lotnicze...

[9] Żurek J., Modelowanie niezawodności nadążnych systemów bezpieczeństwa, Wydawnictwo Instytutu Technologii Eksploatacji, Radom 2010 .

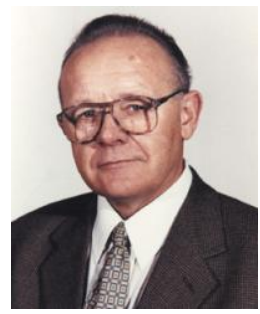

Prof. dr hab. inz. Józef ŻUREK, profesor zwyczajny Instytutu Technicznego Wojsk Lotniczych wWarszawie, zastępca przewodniczacego Rady Naukowej ITWL. Ukończyt Wojskowa Akademię Techniczna. Inicjator, a także wspóttwórca wdrożonych $w$ Siłach Zbrojnych RP systemów ewidencji $i$ przetwarzania danych eksploatacyjnych wojskowych statków powietrznych, które stuża do analizy niezawodności, oceny trwatości techniki lotniczej oraz bezpieczeństwa lotów. Opublikowat wiele prac $z$ dziedziny eksploatacji obiektów technicznych $i$ bezpieczeństwa systemów technicznych. Jest autorem $i$ współautorem kilku publikacji ksiażkowych. Uczestniczyt w tworzeniu nowych kierunków naukowych w Polsce jako organizator $i$ współorganizator wielu konferencji $z$ dziedzin: inżynierii systemów, bezpieczeństwa systemów, eksploatacji obiektów technicznych (Udziat 50\%).

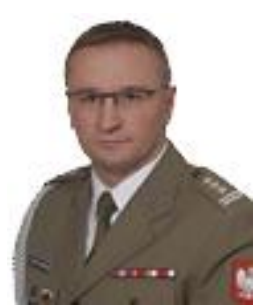

plk dr inz. Jarostaw Ziótkowski jest absolwentem Wydziału Mechanicznego WAT. W roku 2004 uzyskat stopień doktora nauk technicznych $w$ specjalności: modelowanie procesów eksploatacji. Pracuje w Wydziale Logistyki WAT na stanowisku Zastępcy Dziekana. Zajmuje się zagadnieniami modelowania matematycznego procesów eksploatacji, logistyka, tańcuchami dostaw, ekologistyka (Udziat 50\%). 